\title{
Does education improve health in low- and middle income countries? Results from a systematic review
}

\author{
Stephanie Psaki \\ Population Council \\ Barbara Mensch \\ Population Council \\ Erica Chuang \\ Population Council \\ Andrea J. Melnikas \\ Population Council
}

Follow this and additional works at: https://knowledgecommons.popcouncil.org/departments_sbsr-pgy

Part of the Demography, Population, and Ecology Commons, Gender Equity in Education Commons, International Public Health Commons, and the Women's Health Commons How does access to this work benefit you? Let us know!

\section{Recommended Citation}

Psaki, Stephanie, Barbara Mensch, Erica Chuang, and Andrea J. Melnikas. 2019. "Does education improve health in low- and middle income countries? Results from a systematic review," GIRL Center Research Brief no. 5. New York: Population Council. 
GIRL Center Research Brief

No. 5 June 2019

\section{DOES EDUCATION IMPROVE HEALTH IN LOW- AND MIDDLE- INCOME COUNTRIES? RESULTS FROM A SYSTEMATIC REVIEW}

STEPHANIE R. PSAKI, BARBARA S. MENSCH, ERICA K. CHUANG, AND ANDREA J. MELNIKAS

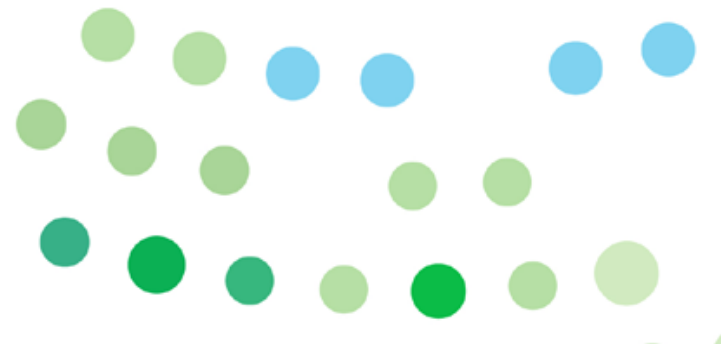


The Girl Innovation, Research, and Learning (GIRL) Center generates, synthesizes, and translates evidence to transform the lives of adolescent girls

popcouncil.org/girlcenter

GIRL Center Research Briefs present new knowledge on issues of current and critical importance and recommend future directions for research, policies, and programs.

Suggested citation: Psaki, S.R., B.S. Mensch, E.K. Chuang, and A.J. Melnikas. 2019. "Does education improve health in low- and middleincome countries? Results from a systematic review." GIRL Center Research Brief No. 5. New York: Population Council.

\section{MORE DETAILS ON THIS STUDY:}

Mensch, B.S., E.K. Chuang, A.J. Melnikas, and S.R. Psaki. 2019.

"Evidence for causal links between education and maternal and child health: systematic review." Trop Med Int Health. 24(5): 504.

Psaki S.R., E.K. Chuang, A.J. Melnikas, D.B. Wilson, and B.S. Mensch. 2019. "Causal effects of education on sexual and reproductive health in low and middle-income countries: A systematic review and metaanalysis." SSM-Population Health. In press, accepted manuscript.

Psaki S.R., B.S. Mensch, E.K. Chuang, and A.J. Melnikas. 2017. "Evidence for causal links between education and maternal and child health, sexual and reproductive health, and malaria: a systematic review." PROSPERO CRD42017073224.

Research reported in this paper was supported by a grant from the Bill \& Melinda Gates Foundation. We thank the members of an advisory group who provided input into the design of the systematic review: Sarah Baird, Jere Behrman, Robert Black, Chris Bonell, Sonalde Desai, Parfait Eloundou-Enyegue, Emmanuela Gakidou and Robert LeVine.

(C) 2019 The Population Council, Inc. 


\section{KEY FINDINGS}

1. Women who complete more schooling have fewer children, but the average effect is small.

2. Schooling has a small protective effect against HIV for women.

3. Women's education leads to a small decrease in the chances of child mortality.

4. Despite assumptions about the effects of education on health, evidence is lacking on key aspects of this relationship.

5. It remains unclear how investments in education may affect health outcomes. 


\section{BACKGROUND}

Over the past few decades, governments in low- and middle-income countries have made substantial investments in expanding access to school. Beyond the goal of improving levels of attainment and learning, this investment has been based, in part, on an expectation that a better educated population would also be a healthier one. Yet despite enormous progress in expanding school enrollment, improvements in health have not always followed. These patterns raise important questions:

Does education, in fact, enable women, men and their families to be healthier? And if so, how?

To fill this gap in knowledge, we conducted a systematic review of the evidence for the effects of education on both sexual and reproductive health and maternal and child health in low- and middle-income countries.

If improvements in education lead to lower levels of child marriage, unwanted fertility, sexually transmitted infections, and child and maternal mortality, then government investments in education will likely have a payoff in terms of improved health for generations. Further, understanding which aspects of education are most important for improving health-whether grade attainment, literacy and numeracy, or the socializing role of the school environment-can provide useful information to governments and other decision-makers when deciding how to invest limited resources.

\section{SUSTAINABLE DEVELOPMENT GOALS}

The United Nations Agenda for Sustainable Development lays out an ambitious agenda of 17 goals, described as "integrated and indivisible."

- Goal 4 aims to ensure inclusive and quality education for all, and to promote lifelong learning.

- Goal 3 focuses on improving health and well-being, including reducing neonatal, child and maternal mortality, and integrating reproductive health into national strategies.

Developing policies and programs to achieve these goals will require clarity on the circumstances in which improvements in education are likely to lead to improvements in health. 


\section{METHODS}

We conducted a systematic review of the peer-reviewed and gray literature for English language articles published in 1990 or later examining the effects of education on sexual and reproductive health, maternal and child health, and malaria. We focused on studies using the necessary design(s) or data analyses to provide evidence of a causal relationship between education and health.

We converted results to a common measure-partial correlation coefficients-in order to compare results across studies. More details about our study methods are included in the published protocol and journal articles.

\section{CORRELATION OR CAUSATION?}

Despite a great deal of discussion by policy-makers and researchers on the links between education and health, questions remain regarding the degree to which this relationship is causal. Claims that education improves health are often based on correlations alone. For example, the fact that educated women have healthier children does not necessarily mean that education leads to better child health; it could be that more educated women come from wealthier families or have stronger abilities, and it is those factors that result in both better education and better child health.

Understanding whether education leads to better health for women (and men) and their children has important policy and program implications. This information can help inform decisions about investing limited resources in the most effective interventions. 
We identified 7,309 articles in our initial search; only 41 articles met our inclusion criteria. The table below shows the number of studies identified for each outcome of interest.

With only two exceptions, all papers limited their measure of education to grade attainment or years of schooling. Only one paper examined the effect of academic skills (literacy on infant and child mortality) on health outcomes, and one paper assessed the effects of school attendance (on stunting).

\section{NUMBER OF STUDIES BY HEALTH OUTCOME}

\begin{tabular}{|l|l|c|}
\hline \multirow{5}{*}{ Sexual and Reproductive Health } & \multicolumn{1}{|c|}{ OUTCOME } & NUMBER OF STUDIES \\
\hline & Age at first sex & 11 \\
\cline { 2 - 3 } & Age at marriage & 22 \\
\cline { 2 - 3 } & Age at first pregnancy/birth & 22 \\
\cline { 2 - 3 } & Contraceptive use & 16 \\
\cline { 2 - 3 } & Parity/fertility & 19 \\
\hline \multirow{5}{*}{ Maternal and Child Health } & HIV/AIDS and STIs & 6 \\
\hline & Infant/neonatal mortality & 9 \\
\cline { 2 - 3 } & Child mortality & 8 \\
\cline { 2 - 3 } & Stunting/weight for height & 8 \\
\cline { 2 - 3 } & Wasting/height for age & 5 \\
\cline { 2 - 3 } & Underweight/weight for age & 3 \\
\hline & Maternal morbidity & 1 \\
\hline
\end{tabular}

To demonstrate the size of the effects of education on certain health outcomes, we compare the effects of education, based on our study, to the effects of other interventions that have been shown to be effective. These comparisons are illustrative only and are not reported in the full scientific papers. 


\section{KEY FINDING 1}

\section{WOMEN WHO COMPLETE MORE SCHOOLING HAVE FEWER CHILDREN.}

We find evidence in support of a small effect of increased grade attainment for women on lower fertility. This effect may operate, in part, through delaying first sex, marriage, or first birth, and through increasing use of contraception-other outcomes included in our study. On average, however, we found no significant effects of increased grade attainment on those outcomes. We did not include abortion-another potential pathway-in this study.

For comparison, the average effect of one additional year of schooling on fertility is approximately 70 percent as large as the effect of an unconditional cash transfer program tested recently. Therefore, the effect of two additional years of education would likely be larger than that of a similar unconditional cash transfer program.

\section{FIGURE 1. EFFECT OF SCHOOLING ON FERTILITY}

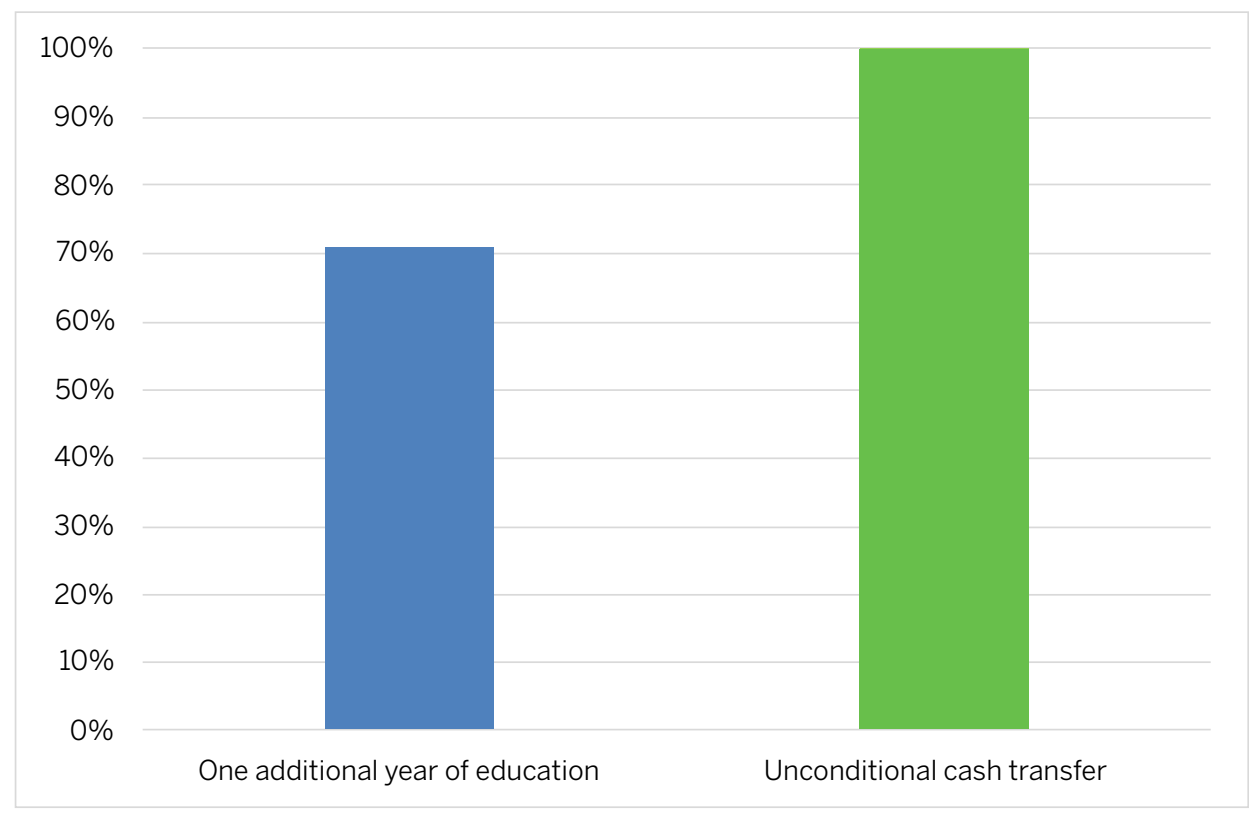

Note: The estimated effect of an unconditional cash transfer (UCT) program comes from an randomized controlled trial (RCT) recently conducted in Malawi. The program included a monthly household UCT of between $\$ 4-\$ 10$, plus an UCT of $\$ 1-\$ 5$ distributed to schoolgirls ages $13-22$, for 10 months. The RCT tested the effects of the UCT on total number of live births two years after the end of the program. (Baird et al. 2019) 
KEY FINDING 2

\section{SCHOOLING HAS A SMALL PROTECTIVE EFFECT AGAINST HIV FOR WOMEN.}

Although we only found four papers examining the effects of education on HIV status (in five countries), the results were consistent in favor of a small effect. Although less evidence was available, we did not find support for an effect of grade attainment on herpes simplex type 2 or syphilis prevalence.

For comparison, the average effect of one additional year of schooling for girls is about 35 percent larger than the effect of pre-exposure prophylaxis (PrEP) demonstrated in a recent RCT among serodiscordant couples (one person is HIV positive, one person is HIV negative) in East Africa.

\section{FIGURE 2. EFFECT OF SCHOOLING ON HIV POSITIVE STATUS}

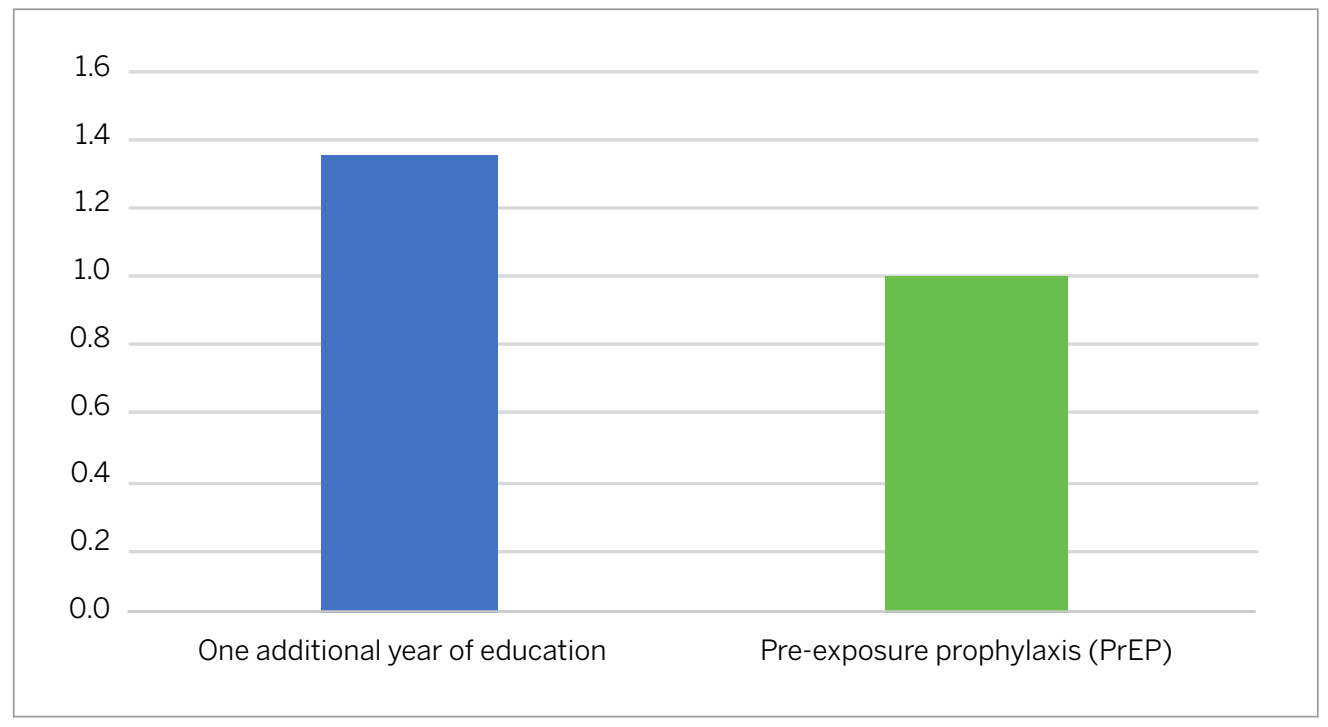

Note: The estimated effect of PrEP comes from an RCT in Kenya and Uganda testing the efficacy of oral tenofovir or Truvada taken daily to prevent HIV among serodiscordant couples at baseline. Participants were followed monthly for up to 36 months. The comparison shown is for the Truvada arm and indicates the effect on the uninfected partner-either male or female (Baeten et al. 2012). 
KEY FINDING 3

\section{WOMEN'S EDUCATION LEADS TO A SMALL DECREASE IN CHILD MORTALITY.}

We found a small but statistically significant effect of mother's schooling on child mortality. For comparison, the effect of one additional year of schooling on child mortality is about 70 percent as large as the effect of a recently tested intervention distributing insecticide treated bed nets in Kenya.

However, we found no effect of education on neonatal or infant mortality, likely reflecting different causes of mortality at these ages. Less evidence was available on the effects of women's grade attainment on child growth, with the exception of stunting, but existing evidence is inconclusive.

\section{FIGURE 3. EFFECT OF SCHOOLING ON CHILD MORTALITY}

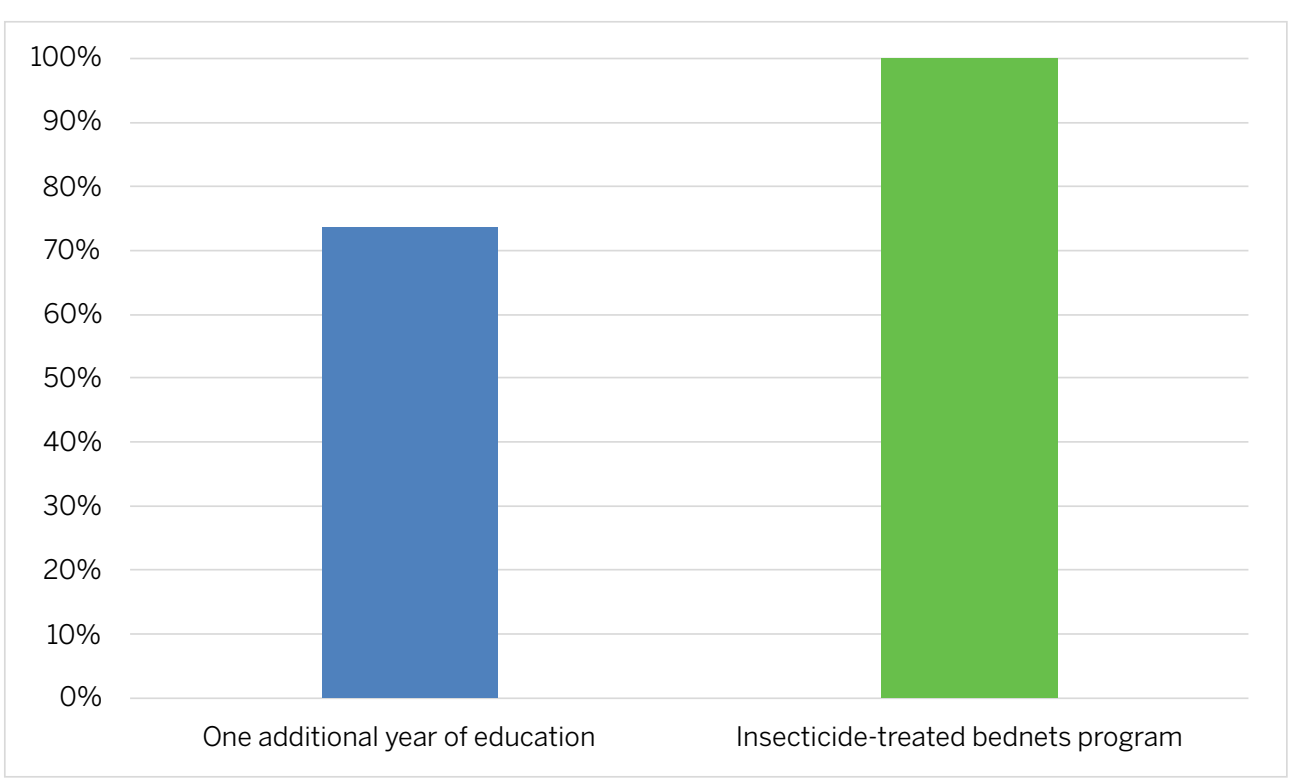

Note: The estimated effect of an insecticide-treated bed nets (ITNs) program comes from a 2003 study that tested a one-time distribution of ITNs in a high malaria transmission area of Western Kenya on under-five mortality from 1998-1999 (Phillips-Howard et al. 2003). 
KEY FINDING 4

\section{DESPITE ASSUMPTIONS ABOUT THE EFFECTS OF EDUCATION ON HEALTH, EVIDENCE IS LACKING ON KEY ASPECTS OF THIS RELATIONSHIP.}

Specifically, we found very limited or no evidence on the following relationships:

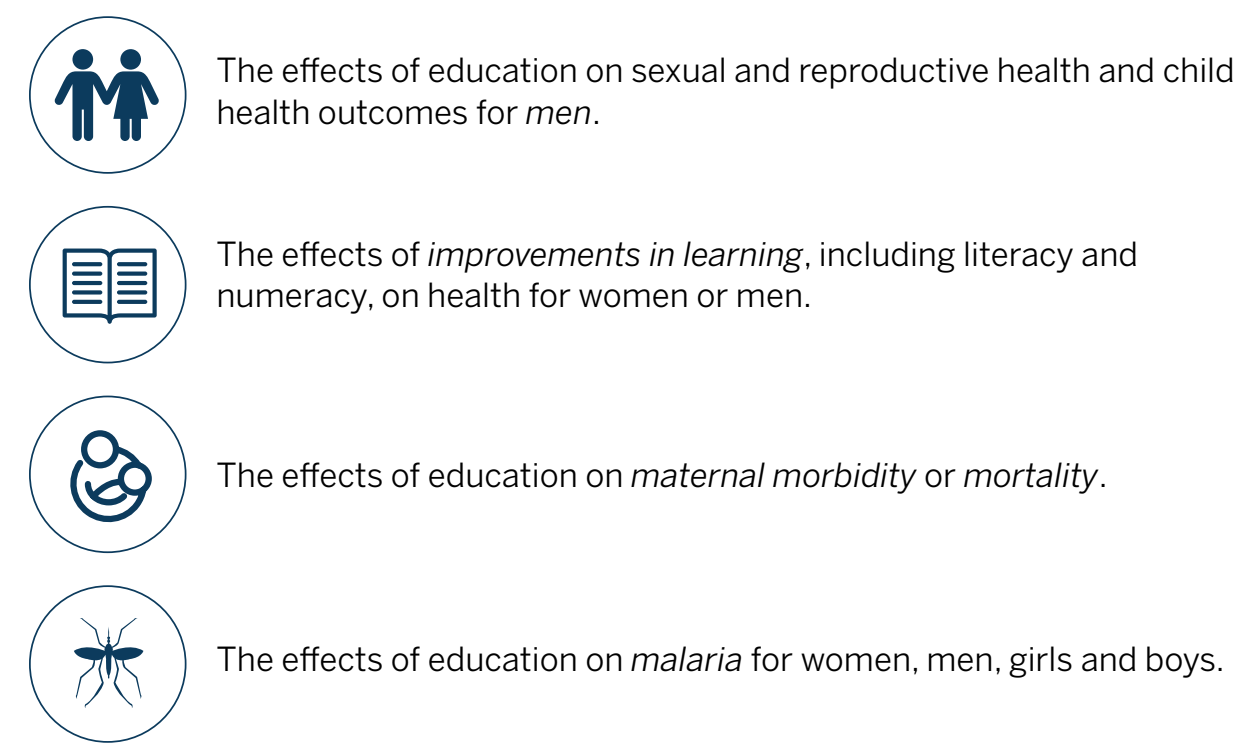

There may very well be strong effects of improved literacy on health, for example, but insufficient studies exist to demonstrate those effects. These are important gaps in the evidence that should be addressed in future research. 


\section{KEY FINDING 5}

\section{IT REMAINS UNCLEAR HOW INVESTMENTS IN EDUCATION MAY AFFECT HEALTH OUTCOMES.}

Many researchers, policy-makers and practitioners have speculated about the ways that education may lead to improved health, summarized in Figure 4. For example, some argue that more years of schooling lead to stronger literacy, which enables women to navigate the healthcare system and provide better care for their children.

Although this review was not designed to test assumptions about the pathways linking education and health, many of the included studies explored these relationships. We found largely inconsistent results on these pathways. Some studies found support for assumed relationships, while others did not. One exception was consistent evidence of an effect of increased grade attainment on improved literacy.

Many more studies undoubtedly exist investigating the effect of education on these pathways, but they were not included in our review as they did not assess the effect on the outcomes we were considering. A clear understanding of the ways that investments in education might improve health is essential to inform more effective interventions.

FIGURE 4. HOW MIGHT EDUCATION LEAD TO BETTER HEALTH?

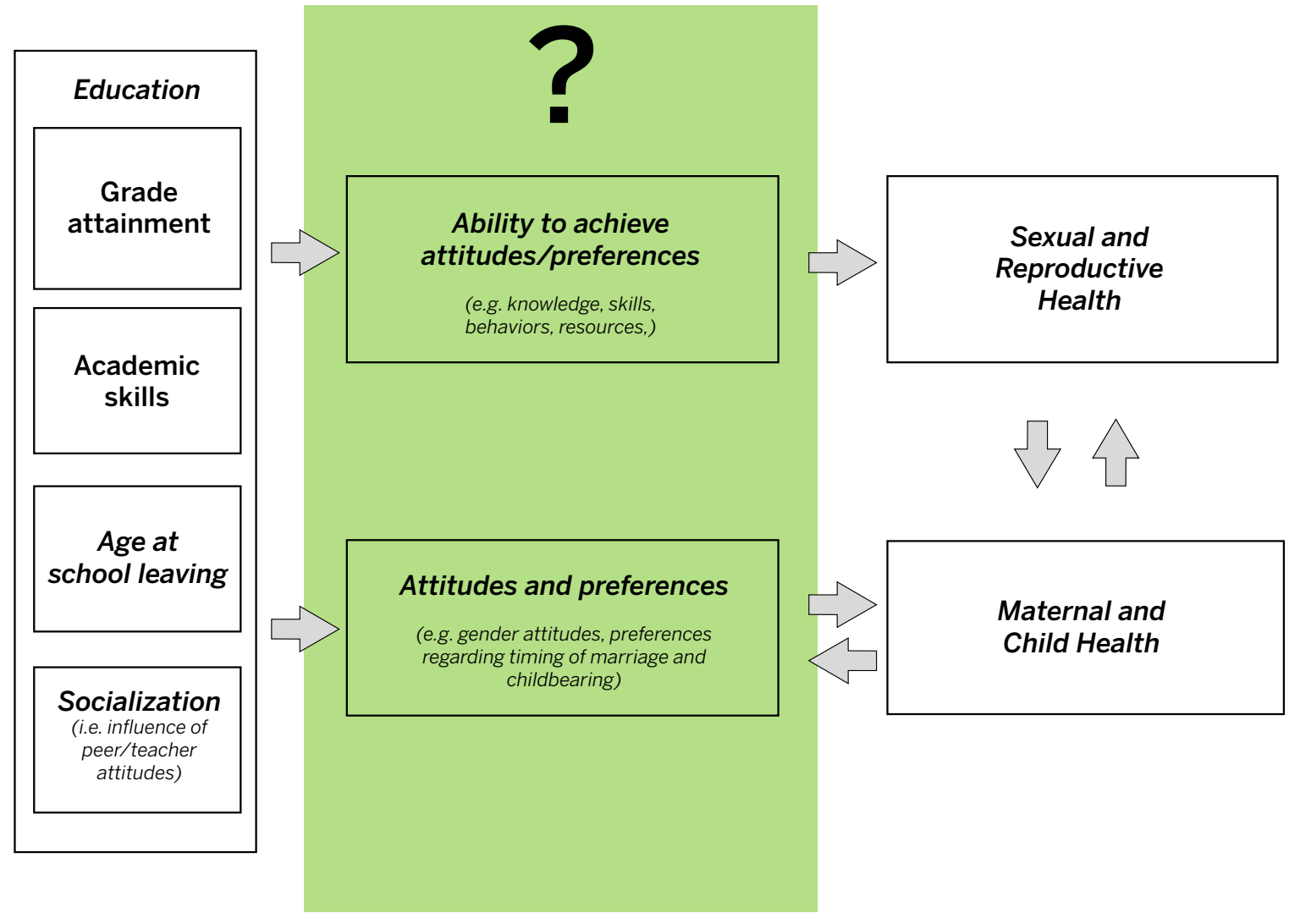




\section{POLICY RECOMMENDATIONS}

\section{Continue to eliminate barriers to school enrollment and attainment.}

Our findings underline the potential health benefit of policies designed to increase schooling, such as those eliminating school fees at the primary level. Although elimination of secondary school fees is more recent, and not yet as widespread, those policies may also have substantial positive effects on education and health outcomes, particularly if sufficient investments are made in improving the quality of schooling.

While national policy changes are one important approach to expanding access to school, there may also be more targeted interventions aimed at increasing enrollment for specific groups. Yet for some groups, particularly those least likely to attend school, policy changes alone may not be sufficient to ensure enrollment and completion of secondary school. More intense efforts may be needed for the most vulnerable groups, and the health benefits may be different (either smaller or larger).

\section{Invest in improving the quality of schooling.}

Many of the studies in our review draw on data from samples of women (and men) who benefited from policy changes soon after they were enacted. However, due to insufficient investments in school facilities to keep up with increased demand, the quality of schooling may have deteriorated in many settings where these policies were enacted. Investments in maintaining-or improving-school quality following increases in enrollment may be necessary to maximize the positive effects of education on health outcomes.

\section{Align education and health goals and investments.}

Despite recognition that education and health are closely linked, policy-making and budgeting for education and health programs often remain siloed. Our study demonstrates that those seeking to improve health outcomes should consider investing resources in women's education, as the U.S. government's DREAMS initiative has done for HIV prevention. While we do not examine the effects of health on educational achievement in this study, the reverse is likely also true: education programs are likely to be most effective in healthy populations. 


\section{REFERENCES}

Baeten, J. M., D. Donnell, et al. 2012. "Antiretroviral Prophylaxis for HIV Prevention in Heterosexual Men and Women." New England Journal of Medicine 367(5): 399-410.

Baird, S., Mclntosh, C., Özler, B. 2018. “When the money runs out: Do cash transfers have sustained effects on human capital accumulation?" World Bank Policy Research Working Paper 7901.

Phillips-Howard, P. A., B. L. Nahlen, et al. 2003. "Efficacy of permethrin-treated bed nets in the prevention of mortality in young children in an area of high perennial malaria transmission in western Kenya." Am J Trop Med Hyg 68(4 Suppl): 23-29. 


\section{GIRL然Center}

FOR INNOVATION, RESEARCH, AND LEARNING

The Girl Innovation, Research, and

Learning (GIRL) Center generates,

synthesizes, and translates evidence to

transform the lives of adolescent girls

popcouncil.org/girlcenter 